\title{
Hodgkin Lymphoma in Remission
}

National Cancer Institute

\section{Source}

National Cancer Institute. Hodgkin Lymphoma in Remission. NCI Thesaurus. Code C158583.

History of Hodgkin lymphoma with no evidence of disease after therapy. 